\title{
Study of a prescribing pattern of empirical antibiotics in patients with sepsis in a tertiary care hospital of Eastern India
}

\author{
Mohanty $L^{1}$, Sahoo $D^{2}$, Panda $S S^{3}$, Patro $S^{4}$ \\ ${ }^{1}$ Dr Lalatendu Mohanty, ${ }^{2}$ Dr. Debananda Sahoo, ${ }^{3}$ Professor S. S. Panda, ${ }^{4}$ Dr. Prof. Shubhransu Patro, all authors are \\ affiliated with Department of Medicine, Kalinga Institute of Medical Sciences, Bhubaneswar, Odisha, India.
}

Address for Correspondence: Dr Lalatendu Mohanty, Department of Medicine, Kalinga Institue of Medical Sciences, Patia, Bhubaneswar, Odisha, India. E-Mail id- m.lalatendu@yahoo.com

\begin{abstract}
Background: Blood stream infections cause significant morbidity and mortality worldwide. Rational use of antimicrobials is required for proper management. Appropriate selection of empirical antibiotic therapy for diagnosed sepsis is difficult. Objective: The main objective of this study is to evaluate the prescribing pattern of antibiotics in patients with sepsis in a tertiary care hospital of Eastern India. Methods: The study was carried over a period of one year at the Department Of Medicine, Kalinga Institute of Medical Sciences (KIMS), Bhubaneswar. We studied 100 patients with sepsis regarding empirical antibiotics prescribed on initial evaluation. Results: As per the prescription analysis, the antibiotics used as empirical treatment based on class were penicillin derivatives (72\%), macrolide (40\%), nitroimidazole (40\%), Cephalosporin (28\%), fluoroquinolones (18\%), aminoglycoside (13\%), Carbapenems (3\%) and oxazolidinone (4\%). $56 \%$ patients received a combination of two antibiotics. We had seen improvement in $86 \%$ of the patients and discharged them. The rest were either shifted to the specialty care or left the hospital against medical advice. Conclusion: This study found that beta-lactam antibiotics like piperacillin, amoxyclav and cephalosporins are mostly used in the empirical treatment of sepsis. Early initiation of antibiotics is associated with improved outcomes in severe sepsis and septic shock. The addition of two or more antibiotics increases the coverage especially of Gram-negative bacteria.
\end{abstract}

Keywords: Blood stream infections, Empirical antibiotics, Sepsis, Gram-positive bacteria, Gram-negative bacteria

\section{Introduction}

Sepsis is caused by introduction of different pathogenic organisms into the human host [1]. Bacterial blood stream infections are a leading cause of significant patient morbidity and mortality [2]. Severe sepsis and septic shock are medical emergencies in medical practice. Severe sepsis or septic shock affects 18 million individuals per year worldwide. Sepsis syndrome is a spectrum of diseases. It ranges from SIRS (systemic inflammatory response syndrome) with possible infection in one end to severe sepsis, septic shock and multiple organ failures in the other end [3-6]. The burden of sepsis on health care is extensive in number; it is the leading cause of death in non-coronary intensive care units (ICUs). Antibiotics are the most

Manuscript received $10^{\text {th }}$ October 2016

Reviewed: $24^{\text {th }}$ October 2016

Author Corrected: $5^{\text {th }}$ November 2016

Accepted for Publication $17^{\text {th }}$ November 2016 frequently prescribed drugs used among hospitalized patients [7]. There are widespread concerns about the appropriate use of these agents both in India and globally. Prescribing drugs is an important skill which needs to be updated continuously. The empirical antibiotic therapy is generally the initial antibiotic regimen started within 24 hours of admission. Patients get antibiotics before the drug sensitivity report [8]. As per international guidelines, the immediate treatment of severe sepsis or septic shock need antibiotic administration within the first hour of recognition as it directly impacts in/on mortality [9]. It is very important to be rationale while choosing the empirical antibiotic. The appropriate selection of empirical antibiotic therapy for positive blood cultures is difficult. Bacteria are only partially identified on Gram stain and drug susceptibility reports will take an additional $24-48$ hours 
after a culture is reported as positive [10]. Antibiotic sensitivity pattern to common pathogen after the use of empirical antibiotics has been changing day by day. So, it is necessary to determine antibiotic sensitivity pattern and do bacteriological analysis in different regions across the world before prescribing antibiotics. Therefore, the purpose of this study was to analyse data on the pattern of empirical antibiotics prescribed in sepsis patients.

\section{Aims and objectives}

The aim of this study is to evaluate the prescribing pattern of antibiotics in patients with sepsis in a tertiary care hospital of Eastern India.

\section{Materials and Methods}

This study was a prospective study, which was conducted for a period of one year from July 2015 to June 2016. One hundred patients with sepsis admitted to the Department Of Medicine of Kalinga Institute of Medical Sciences (KIMS), Bhubaneswar were studied regarding antibiotics prescribed on initial evaluation.

The study included adult patients $\geq 18$ years of age who presented to medicine department during the study period with more than or equal to two of the systemic inflammatory response syndrome (SIRS) criteria as defined by ACCP/SCCM consensus conference [11].
- Temperature $>38^{\circ} \mathrm{C}$ or $<36^{\circ} \mathrm{C}$

- Heart rate $>90$ beats/ minute

- Respiratory rate $>20$ breaths/minute

- $\mathrm{WBC}>12,000$ cells/mm3, <4000 cells/mm3 or $>10$ $\%$ immature (band forms) and had a suspected infection according to medical record.[12]

We excluded postoperative patients, known cases of CKD, acute stroke or ACS and patients who are HIV positive from the study. We collected blood cultures of all the patients immediately after admission and were sent for culture. On receipt of positive culture reports, we analyzed the pattern of antibiotic sensitivity and antibiotics changed wherever applicable. The pattern of drug used and the pattern of organisms grown were evaluated by analyzing the drug prescriptions and the blood culture reports.

The demographic and clinical treatment data of 100 patients was collected in the following format:

- Age and sex of the patient

- Past history of diabetes

- Physical parameters like temperature, heart rate and respiratory rate

- Diagnosis of patients

- The empirical antibiotic used at evaluation

- Average number of antibiotics per patients/patient

\section{Results}

During the study period of one year from July, 2015 to June, 2016 total 100 patients were evaluated, consisting of 48 (48\%) male patients and $52(52 \%)$ females. Based on the diagnostic criteria of sepsis, three groups of WBC count range were identified: count $<4000 / \mathrm{mm} 3,4000-12000 / \mathrm{mm} 3$ and $>12000 / \mathrm{mm} 3$. On analysis, it showed that $8 \%$ of patients had a count less than $4000 / \mathrm{mm} 3$ and $6 \%$ had a count between $4000-12000 / \mathrm{mm} 3$. The majority $86 \%$ had count $>12000 / \mathrm{mm} 3$ and most of the time it is very high (Table.1).

Most common antibiotics used were piperacillin (56\%) and metronidazole (40\%). Most patients (56\%) received a combination of two antibiotics (Fig.1). If we analyze based on the class of antibiotics: Penicillin derivatives (72\%), macrolide (40\%), cephalosporin (28\%), fluoroquinolones (18\%), aminoglycoside (13\%), carbapenems (3\%) and oxazolidinone (4\%) (Fig.2). 48 patients (48\%) had a known history of diabetes mellitus at the time of diagnosis. $86 \%$ of the patients showed improvement and were discharged and the rest were either shifted to specialty care or left the hospital against medical advice.

Table-1: Distribution of patients based on WBC count at diagnosis.

\begin{tabular}{|c|c|c|c|}
\hline Sl. No. & WBC Range & No. of patients & \% \\
\hline 1 & $<4000$ & 8 & 6 \\
\hline 2 & $4000-12000$ & 6 & 86 \\
\hline 3 & $>12000$ & 86 & 8 \\
\hline
\end{tabular}

Results: Majority of patients presented with very high WBC counts 
Table-2: Distribution of empirical antibiotics.

\begin{tabular}{|c|c|c|c|c|c|c|c|}
\hline $\begin{array}{c}\text { Sl. } \\
\text { No. }\end{array}$ & Antibiotic & $\begin{array}{c}\text { No. of } \\
\text { patients }\end{array}$ & $\%$ & $\begin{array}{c}\text { Sl. } \\
\text { No. }\end{array}$ & Antibiotic & $\begin{array}{c}\text { No. of } \\
\text { patients }\end{array}$ & \% \\
\hline 1 & Piperacillin & 56 & 56 & 8 & Amoxyclav & 16 & 16 \\
\hline 2 & Metronidazole & 40 & 40 & 9 & Clarithromycin & 35 & 35 \\
\hline 3 & Ceftazidime & 2 & 2 & 10 & Ceftriaxone & 25 & 25 \\
\hline 4 & Ciprofloxacin & 2 & $2 \%$ & 11 & Azithromycin & 5 & 5 \\
\hline 5 & Netilmycin & 7 & 7 & 12 & Amikacin & 6 & 6 \\
\hline 6 & Ofloxacin & 16 & 16 & 13 & Cefepime & 1 & 1 \\
\hline 7 & Imipenem & 3 & 3 & 14 & Linezolid & 4 & 4 \\
\hline
\end{tabular}

Results: Piperacillin (56\%) is the most common antibiotics used in the study

Table-3: Distribution of patients according to the number of antibiotics prescribed.

\begin{tabular}{|c|c|}
\hline No. of Antibiotics & No. of Patients \\
\hline 1 & 10 \\
\hline 2 & 56 \\
\hline 3 & 28 \\
\hline 4 & 6 \\
\hline
\end{tabular}

Results: Majority of patients with sepsis received a combination of two antibiotics $(56 \%)$

Table-4: Distribution of patients according to the class of antibiotics.

\begin{tabular}{|c|c|}
\hline Class of antibiotics & No. of patients \\
\hline Penicillin group & 72 \\
\hline Macrolide & 40 \\
\hline Nitroimidazole & 40 \\
\hline Fluoroquinolones & 18 \\
\hline Aminoglycosides & 13 \\
\hline Cephalosporins & 28 \\
\hline Oxazolidinediones & 4 \\
\hline Carbapenems & 3 \\
\hline
\end{tabular}

Results: Penicillin (72\%) is the most common class of antibiotics used as empirical treatment of severe sepsis.

\section{Discussion}

The main purpose of the study was to evaluate the prescription pattern of empirical antibiotics at the initial diagnosis of sepsis at the Department of Medicine, KIMS, Bhubaneswar. An audit of prescribing patterns of antibiotics can reflect the quality and standard of clinical practice. Patients had been administered a variety of empirical antibiotics during the study period.

A prescription by a doctor may be taken as a reflection of physician's attitude to the diseases and the role of drug treatment. It also provides an insight into the nature of health care delivery system [13].
Appropriate empirical antibiotics are crucial for the survival of patients with severe sepsis. Formerly, multidrug resistant pathogens were found almost exclusively in nosocomial infections. Recently / It has been observed that the community-acquired infections are now often caused by antibiotic-resistant bacteria (for example, extended-spectrum b-lactamase producing Enterobacteriaceae, multidrug-resistant Pseudomonas aeruginosa, or methicillin-resistant Staphylococcus aureus). This striking change in epidemiology may explain why the initial therapy frequently includes a combination of different antibiotics [14]. 
The choice of empirical antimicrobial therapy depends on a number of complex issues. This might be related to the patient's history, drug intolerances, underlying pathology or disease, the clinical syndrome, and susceptibility patterns of pathogens in the community, in the hospital, and that previously have been documented to colonize or infect the patient [15].

At the American College of Emergency Physicians scientific assembly 2013, the results of a prospective study done on 5787 adults with severe sepsis or septic shock was presented. This study reflected that patients who are managed according to 4 clinical goals (blood cultures before antibiotics, lactate before 90 minutes, IV antibiotics before 180 minutes, and $30 \mathrm{~mL} / \mathrm{kg}$ of IV fluids before 180 minutes) were significantly less likely to die in the hospital than were those for whom all 4 of these goals were not met [16].

Gaieski et al. found overall mortality decreased by $13.7 \%$ in a cohort receiving uniform, algorithmic hemodynamic resuscitation when appropriate antibiotics were administered in less than one hour from triage time $(33.2 \%$ vs. $19.5 \%$; OR $0.3 ; 95 \%$ CI 0.11 to $0.83 ; \mathrm{p}=0.02)[17]$.

The Brazilian Medical Association guidelines on management of sepsis mentioned that broad-spectrum empirical therapy should be used for severe sepsis or septic shock patients, aiming to offer the patient the best early antibiotic therapy. When choosing a broadspectrum therapy, the following criteria should be considered: the primary infective source, the agent's susceptibility according to acquisition (either hospital or community), previous infections and recent antimicrobials use [18].

Hariharan et al reported that $60 \%$ of the patients studied in a Caribbean ICU received combination of two antibiotics [19].

Antibiotic resistance among pathogenic bacteria is a matter of concern worldwide. Widespread and inappropriate use of antimicrobials is an important cause of resistance. Formulation of hospital antibiotic policy based on local susceptibility of the microorganisms is an urgent need [20].

The choice of empiric antibiotic therapy should be based on the most likely source of organisms, clinical settings (community- vs. hospital-acquired sepsis), recent antibiotic use, and local antibiotic resistance patterns. The risk of resistance or super infection can be reduced by narrowing empiric antibiotic therapy once the causative organism has been identified. In 2010, a metanalysis found that combination therapy demonstrated survival benefit and improved clinical response in patients who had septic shock. However, combination antibiotic therapy did not improve sepsis survival compared with monotherapy in hemodynamically stable patients. When there is a risk of Pseudomonas aeruginosa bacteremia, antipseudomonal combination therapy is recommended [21].

Different studies have demonstrated lower mortality and length of stay in patients with pneumococcal bacteremia or with community-acquired pneumonia receiving combination therapy, including a $\beta$-lactam plus a macrolide or a quinolone, than in those receiving monotherapy [22, 23, and 24]. In these studies, the benefits seem to be restricted to more-severe patients or to those in septic shock [22, 25].

There are many studies done on the prescription pattern of antibiotics on neonatal sepsis though studies on adult sepsis are few. In a study by Vaniya et al in neonatal sepsis, the majority of neonates $(92.56 \%)$ were prescribed 2 to 5 antibiotics and $29.59 \%$ of neonates were prescribed two antibiotics. Average number of antibiotics of all patients being admitted was $3.74 \pm$ 1.38. Most frequently used antibiotics in decreasing frequency were Amikacin (97.19\%), ampicillin + sulbactam $(60.17 \%)$,vancomycin $(57.64 \%)$, ceftazidime (38.71\%), cefotaxime (34.22\%), ciprofloxacin (26.23\%), piperacillin + tazobactam $(19.07 \%)[26]$.

In a study by Syed et al most of the patients were managed with 1-2 antibiotics (85\%) and only $13 \%$ received 3-4 antibiotics in ICU, whereas in the northern counter part of the country $70 \%$ patients received 2 or less antibiotics, whereas western countries report still lower antibiotic prescription. Metronidazole, cephalosporins and penicillins are most commonly prescribed antibiotics reported by several studies conducted in ICUs of tertiary care hospitals of our country [27].

In a study conducted by Diaz-Martin et al the most frequently prescribed antibiotic agents were b-lactams $(\mathrm{n}=902 ; 65.7 \%)$, carbapenems $(\mathrm{n}=345 ; 25.1 \%)$, and quinolones $(n=282 ; 20.6 \%)$. It concluded that $\beta$ - 
Lactams, including carbapenems, are the mainstay of empiric therapy in patients with severe sepsis and septic shock. [14]. Our study also found on similar lines that beta-lactam antibiotics like piperacillin, amoxyclav and cephalosporins are mostly used in the empirical treatment of sepsis. The higher rates of antibiotic prescription in our institute could be because of its tertiary settings with many critical patients being referred from other centres.

\section{Conclusion}

Early initiation of antibiotics is associated with improved outcomes in severe sepsis and septic shock. The addition of two or more antibiotics increases the coverage especially of Gram-negative bacteria.

The choice of empirical antibiotics should depend on common bacteria in the community and their susceptibility pattern. It is also important to note that report of antibiotic resistance is increasing at an alarming rate.

A key factor in the development of an antibiotic resistance is inappropriate use of antibiotics. Physicians need to understand that antibiotics are precious and finite resources. And/and unless conscious efforts are made to address the problem of drug resistance, multidrug resistant organism untreatable by ever known antibiotic may emerge reversing the medical progress by ranking and returning as back to pre-antibiotic.

Though early antibiotics initiation is important for sepsis patients the physician should be rationale with the use of antibiotics.

\section{Abbreviations \\ ACCP : The American College of Chest Physicians \\ ACS : Acute Coronary Syndrome \\ CKD : Chronic Kidney Disease \\ HIV : Human Immunodeficiency Virus \\ ICUs : Intensive Care Units \\ SCCM : Society of Critical Care Medicine \\ SIRS : Systemic Inflammatory Response Syndrome \\ WBC : White Blood Cell}

Conflict of Interest: The authors declare that they have no conflict of interest. Informed consent was obtained from all individual participants included in the study. Funding: Nil, Conflict of interest: None initiated
Permission from IRB: Yes

\section{References}

1. Perman SM, Goyal M, Gaieski DF. Initial Emergency department diagnosis and management of adult patients with severe sepsis and septic shock. Scandinavian Journal of Trauma, Resuscitation and Emergency Medicine. 2012 Jun 27; 20:41. DOI: 10. 1186/ 1757-7241-20-41.

2. Dagnew $M$ et al. Bacterial profile and antimicrobial susceptibility pattern in septicemia suspected patients attending Gondar University Hospital, Northwest Ethiopia. BMC Res Notes. 2013 Jul 22; 6: 283. DOI: 10. 1186 / 1756-0500-6-283.

3. Martin GS, Mannino DM, Eaton S, Moss M. The epidemiology of sepsis in the United States from 1979 through 2000. N Engl J Med. 2003 Apr 17; 348 (16):1546-54

4. Angus DC, Linde-Zwirble WT, Lidicker J, Clermont G, Carcillo J, Pinksy MR. Epidemiology of severe sepsis in the United States: analysis of incidence, outcome, and associated costs of care. Crit Care Me. $2001 \mathrm{Jul} ; 29(7)$ : 1303-10.

5. Levy MM, Fink MP, Marshall JC, Abraham E, Angus D, Cook D, Cohen J, Opal SM, Vincent JL, Ramsay G; SCCM /ESICM/ ACCP/ATS /SIS. 2001 SCCM/ESICM/ACCP/ATS/SIS International Sepsis Definitions Conference. Crit Care Med. 2003 Apr; 31 (4): 1250-6.

6. Becker JU, Theodosis C, Jacob ST, Wira CR, Groce NE. Surviving sepsis in low-income and middle-income countries: new directions for care and research. Lancet Infect Dis. 2009 Sep; 9(9): 577-82. DOI: 10.1016/ S1473-3099(09)70135-5.

7. Krivoy N, El Ahal WA, Bar-Lavie Y, Haddad S. Antibiotic prescription and cost patterns in a general intensive care unit. Pharm Pact (Granada). 2007 AprJun; 5(2): 67-73.

8. Meetler J, Simcock M, Sendi P, Widmer AF, Bingisser R, Battegay M, Fluckiger U, Bassetti S. Empirical use of antibiotics and adjustment of empirical antibiotic therapies in a university hospital: a 
prospective observational study. BMC Infectious Diseases. 2007 Mar; 7:21DOI:10.1186/1471-2334-7-21

9. Dellinger RP, Levy MM, Rhodes A, Annane D, Gerlach H, Opal SM, Sevransky JE, Sprung CL, Douglas IS, Jaeschke R, Osborn TM, Nunnally ME,Townsend SR, Reinhart K, Kleinpell RM, Angus DC, Deutschman CS, Machado FR, Rubenfeld GD, Beale RJ, Webb SA, Vincent JL, Moreno R. Surviving sepsis campaign: international guidelines for management of severe sepsis and septic shock. Crit Care Med. 2013 Feb; 41(2): 580-637. DOI: 10.1097/ CCM. 0b013e31827e83af.

10. Perez-Jorge E V, Burdette SD. Antibiotic Therapy for Positive Blood Cultures. [Internet] 2010 [Cited 2016 Oct 24]. Available from: http:// www.antimicrobe.org/e38.asp.

11. Bone RC, Balk RA, Cerra FB, Dellinger RP, Fein AM, Knaus WA, Schein RM, Sibbald WJ. Definitions for sepsis and organ failure and guidelines for the use of innovative therapies in sepsis. The ACCP / SCCM Consensus Conference Committee. American College of Chest Physicians/Society of Critical Care Medicine. Chest. 1992 Jun; 101(6):1644-55.

12. Kumalo A, Kassa T, Marium ZS, Daka D, Tadesse AH. Bacterial Profile of Adult Sepsis and their Antimicrobial Susceptibility Pattern at Jimma University Specialized Hospital, South West Ethiopia. Health Science Journal. 2016 Jan; 10 (2):1-8.

13. Díaz-Martín A ,Martínez-González ML, Ferrer R, Ortiz-Leyba C, Piacentini E, Lopez-Pueyo MJ, MartínLoeches I, Levy MM, Artigas A, Garnacho-Montero J. Antibiotic prescription patterns in the empiric therapy of severe sepsis: combination of antimicrobials with different mechanisms of action reduces mortality. Critical Care. 2012; 16:R223doi: 10.1186/ cc11869.

14. Laporte JR. Towards a healthy use of pharmaceuticals. Development dialogue. 1985; 2: 4855.

15. Severe Sepsis and Septic Shock Antibiotic Guide. [Internet] 2015 Dec 3 [cited 2016 Oct 24]. Available from:http://med.stanford.edu/bugsanddrugs/guidebook/ _jcr_content/main/panel_builder_1454513702/panel_0/ download_1586531681/file.res/Sepsis\%20Antimicrobia $1 \% 20$ Guide.pdf.
16. McNamara D. Severe Sepsis Strategy Significantly Reduces Mortality. [Internet] 2013 Oct 16 [cited 2016 Oct 24]. Available from: http://www.medscape.com/ viewarticle/812674.

17. Gaieski DF, Mikkelsen ME, Band RA, Pines JM, Massone R, Furia FF, Shofer FS, Goyal M. Impact of time to antibiotics on survival in patients with severe sepsis or septic shock in whom early goal-directed therapy was initiated in the emergency department. Crit. Care Med.2010Apr;38(4):1045-53.DOI: 10.1097/CCM. 0b013e3181cc4824

18. Salomão R, Diament D, Rigatto O, Gomes B, Silva E, Carvalho NB Machado FR. Rev Bras Ter Intensiva. 2011; 23(2):145-57.

19. Hariharan S, Pillai G, McIntosh D, Bhanji Z, Culmer L, Harper-McIntosh K. Prescribing patterns and utilization of antimicrobial drugs in a tertiary care teaching hospital of a Caribbean developing country. Fundam Clin Pharmacol. 2009 Oct;23(5):609-15. doi: 10.1111/j.1472-8206.2009.00713.x. Epub 2009 Jul 28.

20. Shankar RP, Partha P, Shenoy N K, Easow JM , Brahmadathan KN. Prescribing pattern of antibiotics and sensitivity patterns of common microorganisms in the Internal Medicine ward of a teaching hospital in Western Nepal: a prospective study. Ann Clin Microbiol Antimicrob. 2003 Jul 16;2:7.

21. Gauer RL. Early Recognition and Management of Sepsis in Adults: The First Six Hours. Am Fam Physician. 2013 Jul; 88(1):44-53.

22. Baddour LM, Yu VL, Klugman KP, Feldman C, Ortqvist A, Rello J, Morris AJ, Luna CM, Snydman DR, Ko WC, Chedid MB, Hui DS, Andremont A, Chiou CC. Combination antibiotic therapy lowers mortality among severely ill patients with pneumococcal bacteremia. Am J Respir Crit Care Med. 2004 Aug; 170 (4):440-4.DOI: http://dx.doi.org/10. 1164/ rccm. 200311-15780C

23. Lodise TP, Kwa A, Cosler L, Gupta R, Smith RP. Comparison of beta-lactam and macrolide combination therapy versus fluoroquinolone monotherapy in hospitalized Veterans Affairs patients with community acquired pneumonia. Antimicrob Agents Chemother. 2007 Nov; 51 (11): 3977-82. DOI: 10. 1128/ AAC. 00006-07. 
24. Tessmer A, Welte T, Martus P, Schnoor M, Marre R, Suttorp N. Impact of intravenous \{beta\}-lactam/ macrolide versus \{beta\}-lactam monotherapy on mortality in hospitalized patients with communityacquired pneumonia. J Antimicrob Chemother. 2009 May; 63 (5): 1025-33. doi: 10.1093/jac/dkp088. Epub 2009 Mar 17.

25. Rodriguez A, Mendia A, Sirvent JM, Barcenilla F, de la Torre-Prados MV, Sole-Violan J, Rello J: Combination antibiotic therapy improves survival in patients with community-acquired pneumonia and shock. Crit Care Med. Jun 2007, 35: 1493-1498. DOI: 10.1097/01.CCM.0000266755.75844.05.

26. Vaniya HV, Agrawa JMl, Patel NM, Trivedi HR, Balat JD, Jadav SP, Chawda D A. Antimicrobial drug utilization pattern in neonatal sepsis in a tertiary care hospital Clin Exp Res. 2014; 2(2): 110-14. DOI: 10. 5455/jcer.201422

27. Syed MHN, Kumar C U, Shobha JC. Prescription Patterns of Antibiotics in Acute Medical Care Unit of a Tertiary Care Hospital in India. Int.J. Curr. Microbiol. App.Sci.2014;3(7):673-679.

\section{How to cite this article?}

Mohanty L, Sahoo D, Panda S S, Patro S. Study of a prescribing pattern of empirical antibiotics in patients with sepsis in a tertiary care hospital of Eastern India. Int J Med Res Rev 2016;4(11):2039-2045.doi:10.17511/ijmrr. 2016.i11.24. 